\title{
Association between metal cobalt exposure and the risk of congenital heart defect occurrence in offspring: a multi-hospital case-control study
}

Nannan Zhang ${ }^{1 \dagger}$, Shuihua Yang ${ }^{2 \dagger}$, Jiaxiang Yang ${ }^{3}$, Ying Deng ${ }^{1}$, Shengli $\mathrm{Li}^{1,4}, \mathrm{Nana}^{\mathrm{Li}} \mathrm{i}^{1}$, Xinlin $\mathrm{Chen}^{5}$, Ping Yu ${ }^{1}$, Zhen Liu' ${ }^{1 *}$ and Jun Zhu' ${ }^{1 *}$

\begin{abstract}
Background: Many studies have investigated heavy metal exposure could increase the occurrence of congenital heart defects (CHDs). However, there are limited data regarding the relationship between cobalt exposure and CHD occurrence in offspring. The aim of this study was to analyze the association between cobalt exposure in mothers and the risk of CHDs in offspring.

Materials and methods: In order to explore the association between cobalt exposure and occurrence of congenital heart defect (CHD), a case-control study with 490 controls and 399 cases with CHDs in China were developed. The concentrations of cobalt in hair of pregnant woman and fetal placental tissue were measured and processed by a logistic regression analysis to explore the relationship between cobalt exposure and risk of CHDs.

Results: The median concentration of hair cobalt in the control and case group was $0.023 \mathrm{ng} / \mathrm{mg}$ and $0.033 \mathrm{ng} / \mathrm{mg}$ $(\mathrm{aOR}, 1.837 ; 95 \% \mathrm{Cl}, 1.468-2.299 ; P<0.001)$, respectively. And the median (5-95\% range) fetal placental cobalt concentrations were $19.350 \mathrm{ng} / \mathrm{g}$ and $42.500 \mathrm{ng} / \mathrm{g}(\mathrm{aOR}, 2.924 ; 95 \% \mathrm{Cl}, 2.211-3.868 ; P<0.001)$ in the control and case groups, respectively. Significant differences in the middle level of cobalt in hair were found in the different CHD subtypes, including septal defects, conotruncal defects, right ventricular outflow tract obstruction, and left ventricular outflow tract obstruction $(P<0.001)$. Dramatically, different cobalt concentrations in fetal placental tissue were found in all subtypes of cases with CHDs $(P<0.01)$.
\end{abstract}

Conclusions: The finding suggested that the occurrence of CHDs may be associated with cobalt exposure.

Keywords: Cobalt, Metal exposure, Congenital heart defect, Hair biomarker, Placenta tissue

\footnotetext{
*Correspondence: liuzhen5_1@163.com; zhujun028@163.com

${ }^{\dagger}$ Nannan Zhang and Shuihua Yang contributed equally to this work.

${ }^{1}$ National Center for Birth Defect Monitoring, Key Laboratory of Birth Defects

and Related Diseases of Women and Children, Ministry of Education, West

China Second University Hospital, and State Key Laboratory of Biotherapy,

Sichuan University, Sec. 3 No.17, South Ren Min Road, Chengdu 610041,

Sichuan, People's Republic of China

Full list of author information is available at the end of the article
}

(c) The Author(s). 2020 Open Access This article is licensed under a Creative Commons Attribution 4.0 International License, which permits use, sharing, adaptation, distribution and reproduction in any medium or format, as long as you give appropriate credit to the original author(s) and the source, provide a link to the Creative Commons licence, and indicate if changes were made. The images or other third party material in this article are included in the article's Creative Commons licence, unless indicated otherwise in a credit line to the material. If material is not included in the article's Creative Commons licence and your intended use is not permitted by statutory regulation or exceeds the permitted use, you will need to obtain permission directly from the copyright holder. To view a copy of this licence, visit http://creativecommons.org/licenses/by/4.0/ The Creative Commons Public Domain Dedication waiver (http://creativecommons.org/publicdomain/zero/1.0/) applies to the data made available in this article, unless otherwise stated in a credit line to the data. 


\section{Introduction}

Congenital heart defects (CHDs) have an incidence of 6-8 per 1000 at birth [1] and are the leading cause of perinatal and infant death [2]. Patients with CHDs require long-term specialty care according to the severity of the defect [3, 4]. Epidemiologic studies showed that patients with $\mathrm{CHD}$ have an accompanying great economic burden for families and society [5]. CHDs, a multifactorial complex disease, could be caused by genetic factors and environmental factors [6, 7]. Environmental factors were one of the most important pathogenic factors of $\mathrm{CHD}$, such as exposure to hypoxia, nitrogen dioxide, dilantin, halogenated hydrocarbons, and retinoic acid, increasing the risk of CHD [8-10].

Many studies have shown that exposure to metals, such as lead, barium, cadmium, arsenic, and copper, also increases the risk of CHDs [11, 12]. Cobalt (Co), a relatively rare element in the Earth's crust, is essential to mammals in the form of cobalamin (vitamin B12) [13]. Cobalt metal, salts, hard metals, oxides, and alloys are the most commercially important cobalt compounds [14]. Cobalt can be found in the air, seawater, forest fire, volcanic eruptions, and erosion [15]. Anthropogenic use is also the main source of cobalt exposure, such as fossil fuel, engine emissions, Co-containing alloys, diamond polishing, and steel [15]. Diet, inhalation air, and drinking water are also the main source of cobalt in the general population [16]. The highest levels of Co are found in chocolate, green leafy vegetables, fresh cereals, offa, coffee, fish, and nuts [17]. Cobalt may originate from environmental sources, such as food processing and packaging, industrial, or other anthropogenic activities [18]. High concentrations of cobalt exposure may be observed in certain occupations, such as hard metal alloy processing and prosthesis use [19]. Inhalation of cobalt dust represents the main source of exposure in occupational workers [20]. Therefore, the sources and pathways of human cobalt exposure are diverse.

Cobalt plays an important role in nucleic acid synthesis, amino acid synthesis, erythrocyte formation, and vitamin B12 formation [21]. Cobalt accumulates primarily in the heart, pancreas, liver, and kidney, with the relative content in skeletal muscle and the skeleton increasing with time after cobalt uptake [22]. However, cobalt exposure could cause allergic contact dermatitis, asthma, lung fibrosis, hepatotoxicity, and caners $[19,23$, 24]. Exposure to cobalt also leads to nervous system injury, for example memory loss, neuropathies, optic atrophy, and bilateral nerve deafness $[15,25]$. Cobalt metal and salts (mainly cobalt chloride and cobalt sulfate) have genotoxicity, including micronuclei or DNA damage and chromosomal aberrations, probably due to oxidative stress [26]. Additionally, cobalt exposure could induce adult cardiovascular diseases. Animal studies showed that exposure to $2.0-7.6 \mathrm{mg} \mathrm{Co} / \mathrm{kg}$-day led to cardiovascular toxic effects [21]. Worker exposure to cobalt (0.1$5 \mathrm{mg} \mathrm{Co} / \mathrm{m}^{3}$ ) had a higher risk of cardiovascular diseases, including dilative cardiomyopathy, higher heart rate, coronary heart disease, hypertension, and valvular heart disease [27-29]. Animal studies also showed that mice consuming cobalt in the drinking water led to reproductive toxicity, including a reduction in fertility, a decrease in the number of implantation sites and viable fetuses, and a loss of testicular weight [30]. Above all, high levels of cobalt exposure have been a serious threat to environmental safety and public health.

However, research has paid little attention to the association between cobalt levels and the risk of congenital heart defects. The purpose of this study was to examine the interaction between cobalt exposure and CHDs. In this study, we collected clinical data and analyzed the cobalt concentration in pregnant mothers' hair and fetus' placenta tissues to investigate the association between maternal cobalt exposure and the risk of occurrence of CHDs in offspring.

\section{Materials and methods Study population}

The case-control study was conducted from August 2010 to July 2013 at five maternal and child hospital in the cities of Fuzhou, Zhengzhou, Shenzhen, Wuhan and Xi'an, China. Fetuses diagnosed with cardiac defects prenatally were selected as the cases. Pregnant woman who had healthy fetus was selected in the same hospital with gestation ages within 2 weeks differ from the case fetus. All live cases and controls were examined by pediatric cardiologists within the first week after clinical diagnosis by heart auscultation and neonatal echocardiography. Terminated pregnancies or stillbirths were established according to autopsy reports. Then, all clinical data and samples were collected after recruitment. More details regarding the recruitment procedure were provided in our previous study [11]. Each participant was informed during the enrolment process. The study was approved by the Ethics Committee of Sichuan University (No. 2010004).

The gestational ages of all subjects ranged from 14 to 40 weeks, and exclusion criteria for cases and controls included (1) mothers unwilling to participate or with mental disease or dyed hair, (2) fetuses with chromosomal abnormalities or hereditary syndrome or unclear diagnosis, (3) multi-fetal pregnancy, and (4) fetuses with CHD family history. All CHD cases were divided into six major categories according to the anatomic lesion as described in a previous study [12]: (a) septal, (b) conotruncal, (c) right-sided obstructive, (d) left-sided obstructive, (e) anomalous venous return, and (f) other cardiac structural abnormalities. 
Table 1 Descriptive characteristics of the study sample

\begin{tabular}{|c|c|c|c|c|}
\hline Variable & Control, $n=490(\%)$ & Cases, $n=399(\%)$ & Chi square & $P$ value \\
\hline Maternal age $(\text { years, } n)^{a}$ & & & 7.803 & 0.099 \\
\hline$n<20$ & $12(2.4)$ & $12(3.0)$ & & \\
\hline $20 \leq n<25$ & $111(22.7)$ & $113(28.3)$ & & \\
\hline $25 \leq n<30$ & $216(44.1)$ & $179(44.9)$ & & \\
\hline $30 \leq n<35$ & $108(22.0)$ & $73(18.3)$ & & \\
\hline$n \geq 35$ & $43(8.8)$ & $22(5.5)$ & & \\
\hline Gestational age $(\text { week, } n)^{\text {a }}$ & & & 37.628 & $<0.001^{* * *}$ \\
\hline$n<15$ & $6(1.2)$ & $2(0.5)$ & & \\
\hline $15 \leq n<20$ & $69(14.1)$ & $15(3.8)$ & & \\
\hline $20 \leq n<25$ & $233(47.6)$ & $182(45.6)$ & & \\
\hline $26 \leq n<31$ & $109(22.2)$ & $136(34.1)$ & & \\
\hline$n \geq 31$ & $73(14.9)$ & $64(16.0)$ & & \\
\hline Folic acid supplement & & & 11.350 & $0.001^{* *}$ \\
\hline Yes & $436(89.0)$ & $323(81.0)$ & & \\
\hline No & $54(11.0)$ & $76(19.0)$ & & \\
\hline Parental smoking & & & 15.615 & $<0.001^{* * *}$ \\
\hline Yes & $181(36.9)$ & $200(50.1)$ & & \\
\hline No & $309(63.1)$ & $199(49.9)$ & & \\
\hline $\mathrm{ppBMI}\left(\mathrm{kg} / \mathrm{cm}^{2}\right)$ & & & 3.987 & 0.136 \\
\hline $\mathrm{BMI}<18.5$ & $120(23.1)$ & $116(27.6)$ & & \\
\hline $18.5 \leq \mathrm{BMI}<25$ & $381(73.3)$ & $295(70.2)$ & & \\
\hline $\mathrm{BMI} \geq 25$ & $19(3.7)$ & $9(2.1)$ & & \\
\hline mEDU & & & 38.113 & $<0.001^{* * *}$ \\
\hline Primary school and below & $3(0.6)$ & $16(4.0)$ & & \\
\hline Junior middle school & $77(15.7)$ & $114(28.6)$ & & \\
\hline Senior high school & $124(25.3)$ & $89(22.3)$ & & \\
\hline College degree and above & $284(58.0)$ & $173(43.4)$ & & \\
\hline
\end{tabular}

${ }^{a}$ Using base data in following multivariate analysis as continuous variables

${ }^{* *} P<0.01,{ }^{* * *} P<0.001$, two-tailed test, there was statistically significant difference between groups

Table 2 Descriptive statistics for hair cobalt level in the case and control groups

\begin{tabular}{lllllllll}
\hline & \multicolumn{3}{l}{ Hair cobalt $(\mathrm{ng} / \mathrm{mg})$} & & & \\
\cline { 2 - 8 } & $n$ & AM & 5 th $p$ & 25 th $p$ & Median & 75 th $p$ & 95 th $p$ & $P$ value \\
\hline Control & 326 & 0.045 & 0.007 & 0.013 & 0.023 & 0.040 & 0.174 \\
All case & 269 & 0.047 & 0.016 & 0.023 & 0.033 & 0.055 & 0.134 & $<0.001^{* * *}$ \\
Case with septal defects & 183 & 0.047 & 0.016 & 0.023 & 0.0318 & 0.054 & 0.140 & $<0.001^{* * *}$ \\
Case with conotruncal defects & 133 & 0.045 & 0.016 & 0.023 & 0.032 & 0.048 & 0.117 & $<0.001^{* * *}$ \\
Case with right ventricular outflow tract obstruction & 123 & 0.045 & 0.017 & 0.027 & 0.034 & 0.054 & 0.122 & $<0.001^{* * *}$ \\
Case with left ventricular outflow tract obstruction & 42 & 0.051 & 0.015 & 0.022 & 0.030 & 0.052 & 0.154 & $<0.001^{* * *}$ \\
Case with anomalous pulmonary venous return & 42 & 0.086 & 0.013 & 0.025 & 0.032 & 0.099 & 0.326 & $0.001^{* * *}$ \\
Other heart defects & 48 & 0.045 & 0.014 & 0.022 & 0.034 & 0.060 & 0.115 & $0.001^{* * *}$ \\
\hline
\end{tabular}

$n$ number; $A M$ arithmetic means; 5 th $p$, 95th $p$ lead level in 5\%, 95\% percentiles respectively

${ }^{* * *} P<0.001$, two-tailed test, Wilcoxon-Mann-Whitney on nonparametric test compared to the control group 


\section{Questionnaire interview and sample collection}

All participants recruited in the study received a face-toface interview during the antenatal examination. The questionnaire information was obtained as follows: pregnancy history, working and living environment, life style, maternal diet and nutrition, drug use history, family history, maternal illness, and folic acid supplementation. Information regarding potential confounders was obtained for covariate analysis.

Maternal hairs weighing $0.1 \mathrm{~g}$ and 3 to $5 \mathrm{~cm}$ long were collected from the occipital area after the interview.
Placental tissues of approximately $1 \mathrm{~cm}^{3}$ were sheared from the fetal surface of the placenta after delivery. All samples were kept in individual labeled sterile microtubes and frozen at $-80^{\circ} \mathrm{C}$ until use. More details of sample collection were provided in previous studies [31].

\section{Concentration analysis of cobalt in human tissues}

Human hair standard reference materials (GBW09101) were obtained from the Shanghai Institute of Nuclear Research. The cobalt concentrations of the samples were analyzed as described previously using an Agilent

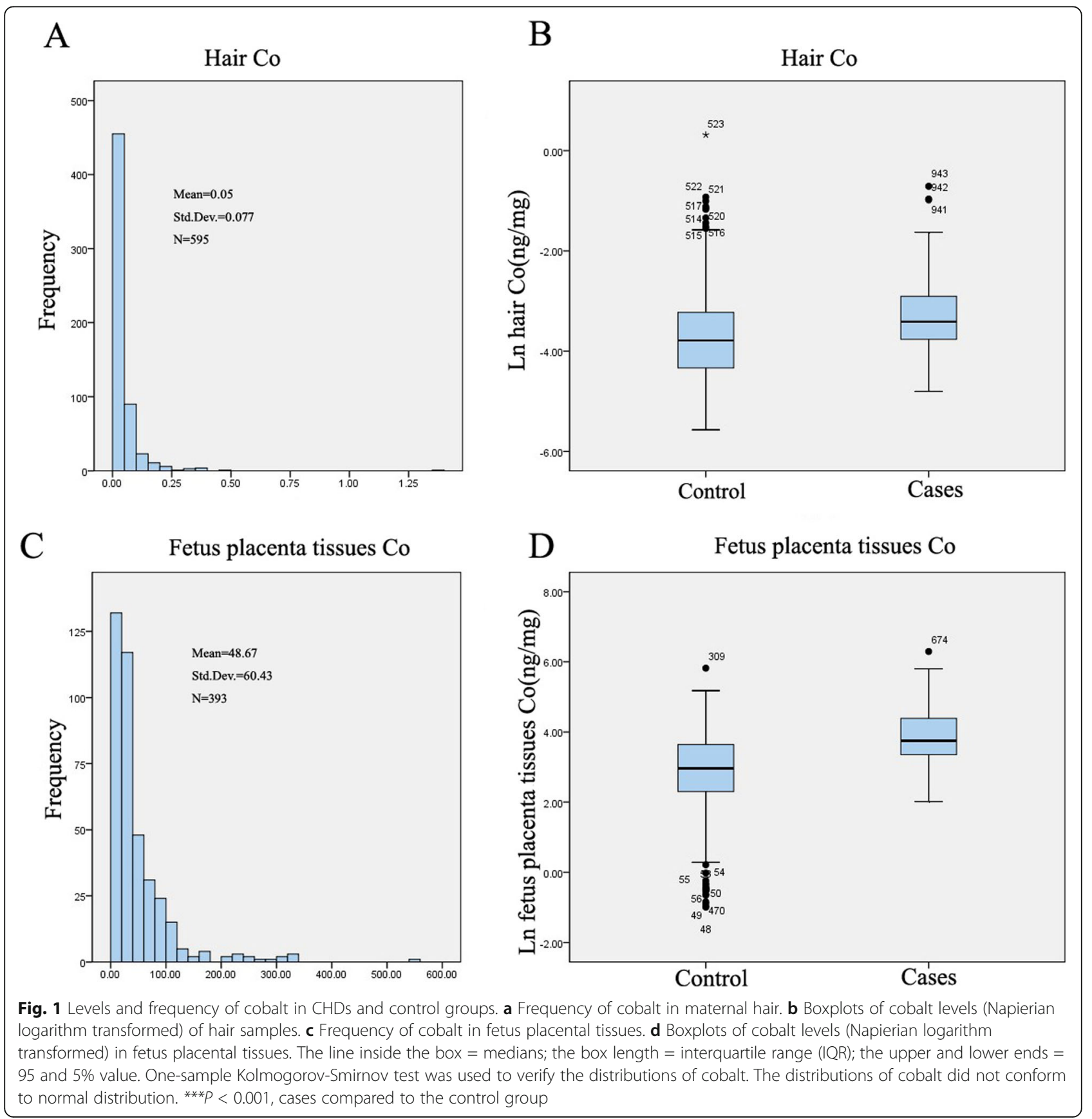


7500cx ICP/MS system (Agilent Technologies; Wilmington, DE) equipped with a G3160b I-AS integrated autosampler [32]. Metals including iron (Fe) and calcium (Ca) were measured together with cobalt from same hairs of these study participants. The limit of detection for cobalt in hair was $0.01 \mathrm{ng} / \mathrm{mg}$, and that for cobalt in placenta tissue was $0.40 \mathrm{ng} / \mathrm{g}$ and the limit detected concentration of iron was $0.01 \mathrm{ng} / \mathrm{mg}$ in hair and $0.18 \mathrm{ng} / \mathrm{g}$ in placenta tissues, respectively. The detection limit for calcium was $0.1 \mathrm{ng} / \mathrm{mg}$ in hair and $0.89 \mathrm{ng} / \mathrm{g}$ in placenta tissues, respectively.

\section{Statistical analysis}

Data analysis was performed using the SPSS 17.0 software (Chicago, IL, USA). A case-control analysis was performed to assess the potential effects of cobalt using data from identified cases and controls. Differences in demographic information and maternal characteristics between the control and case groups were compared by chi-square tests (two-tailed values of $P<0.05$ ). The distributions of cobalt concentration were analyzed by onesample Kolmogorov-Smirnov tests. The distributions of cobalt levels are presented as medians, arithmetic means,

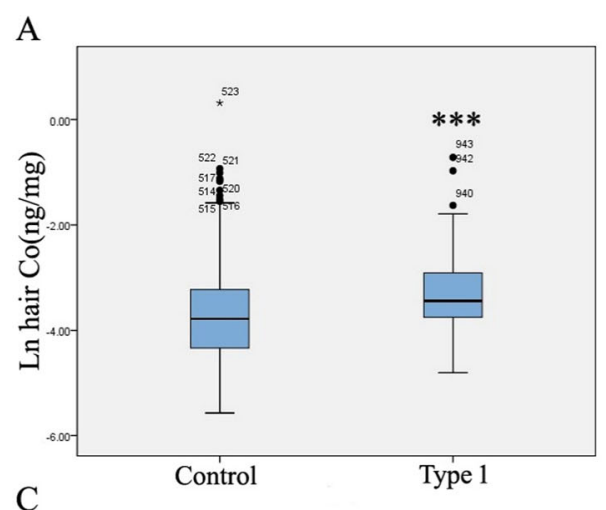

B
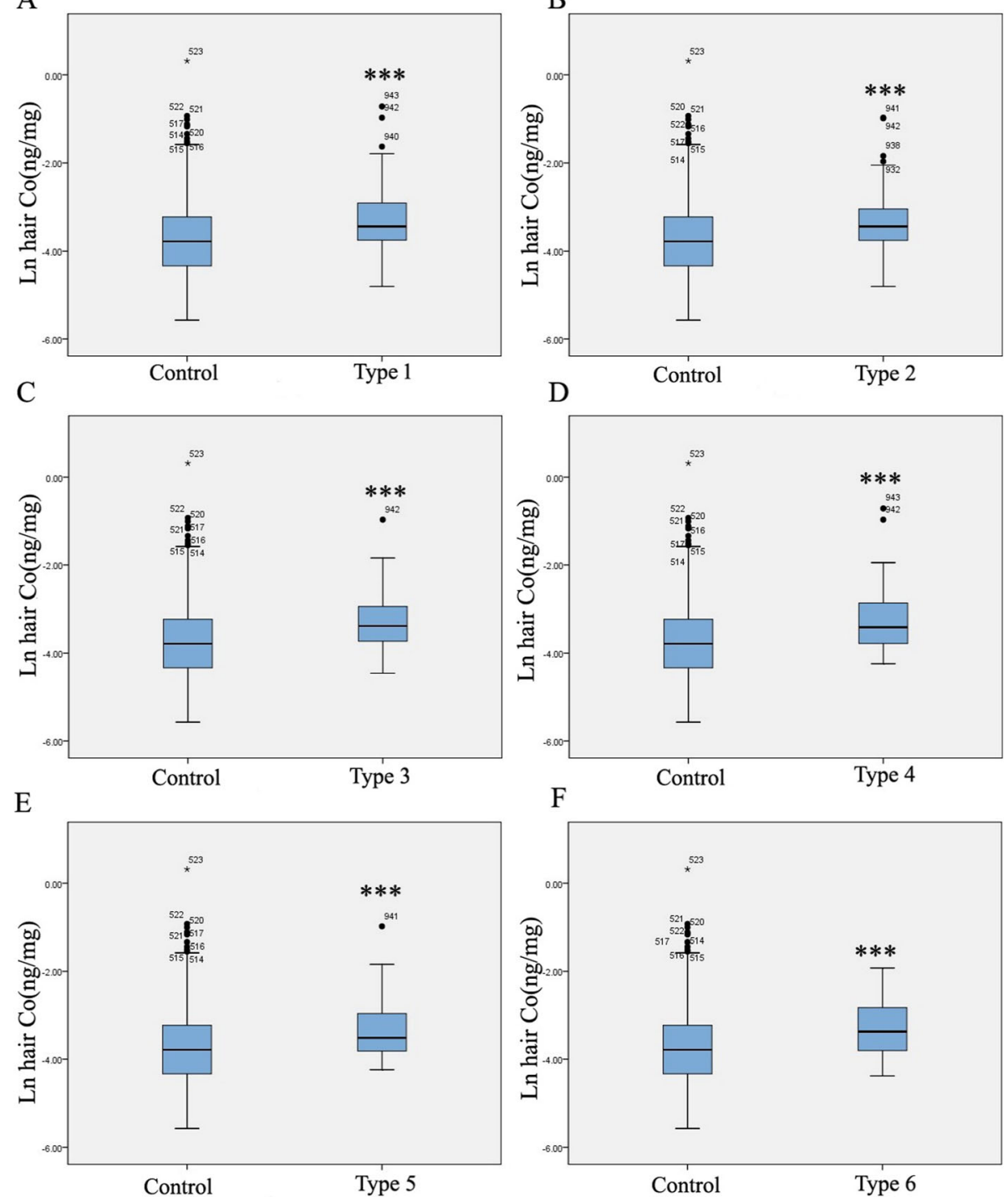

Fig. 2 Levels of hair cobalt in CHD subtypes and control groups. Boxplots of cobalt levels (Napierian logarithm transformed) of hair samples. The line inside the box = medians; the box length = interquartile range (IQR); the upper and lower ends $=95$ and $5 \%$ value. One-sample Kolmogorov-Smirnov test was used to verify the distributions of cobalt. ${ }^{* * *}>0.001$, cases compared to the control group. Type 1 , septal defect; type 2, conotruncal defects; type 3, right ventricular outflow tract obstruction; type 4, left ventricular outflow tract obstruction; type 5, anomalous pulmonary venous return; type 6, other heart defects 
Table 3 Descriptive statistics for placental tissue cobalt level in the case and control groups

\begin{tabular}{|c|c|c|c|c|c|c|c|c|}
\hline & \multicolumn{8}{|c|}{ Tissue cobalt (ng/g) } \\
\hline & $n$ & AM & 5th $p$ & 25th $p$ & Median & 75th $p$ & 95th $p$ & $P$ value \\
\hline Control & 212 & 30.705 & 0.617 & 9.965 & 19.350 & 38.233 & 97.834 & \\
\hline All cases & 181 & 69.701 & 14.431 & 28.465 & 42.500 & 81.175 & 241.959 & $<0.001^{* * *}$ \\
\hline Case with septal defects & 124 & 71.953 & 13.550 & 29.660 & 45.230 & 85.458 & 239.226 & $<0.001^{* * *}$ \\
\hline Case with conotruncal defects & 96 & 65.971 & 12.883 & 26.450 & 38.960 & 77.843 & 244.043 & $<0.001^{* * *}$ \\
\hline Case with right ventricular outflow tract obstruction & 65 & 69.966 & 16.378 & 33.270 & 57.540 & 94.035 & 190.738 & $<0.001^{* * *}$ \\
\hline Case with left ventricular outflow tract obstruction & 29 & 61.630 & 12.880 & 29.575 & 36.260 & 73.260 & 241.515 & $0.001^{* * *}$ \\
\hline Case with anomalous pulmonary venous return & 26 & 66.883 & 7.560 & 22.903 & 42.330 & 89.230 & 245.033 & $0.003^{* *}$ \\
\hline Other heart defects & 32 & 64.142 & 19.143 & 32.940 & 38.585 & 54.775 & 250.074 & $<0.001^{* * *}$ \\
\hline
\end{tabular}

$n$ number; $A M$ arithmetic means; 5 th $p$, 95th $p$ lead level in 5\%,95\% percentiles respectively

${ }^{*} P<0.05$ or ${ }^{* *} P<0.01$, two-tailed test, Wilcoxon-Mann-Whitney on nonparametric test compared to the control group

A

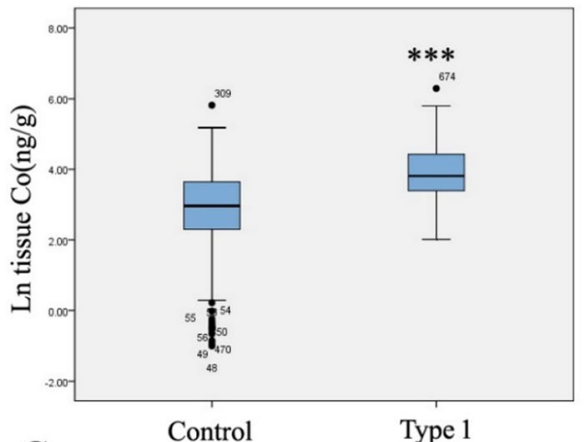

$\mathrm{C}$

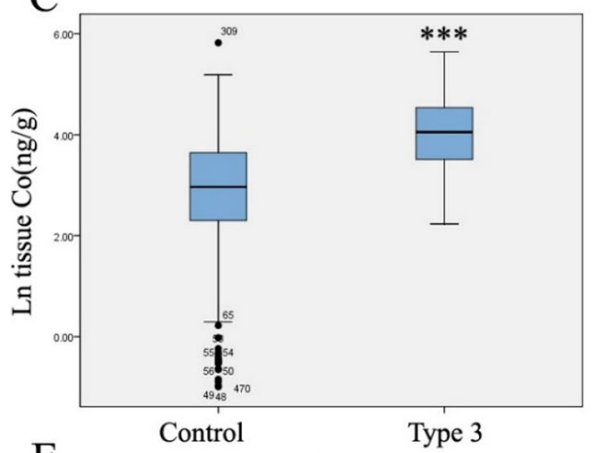

$\mathrm{E}$

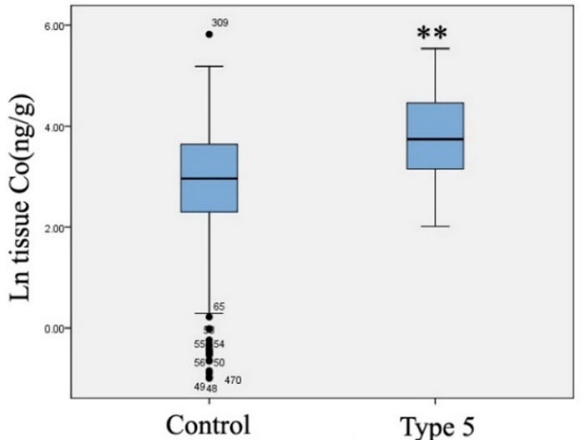

B

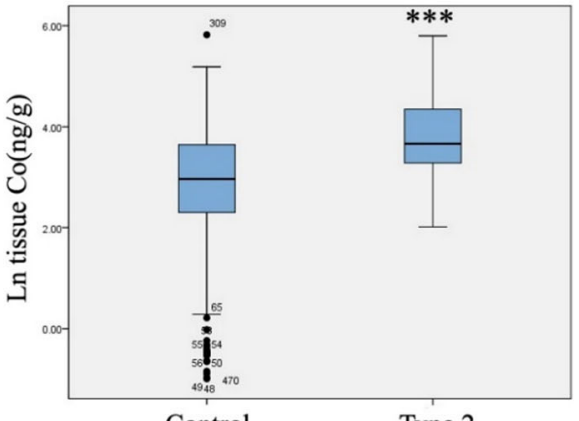

$\mathrm{D}$
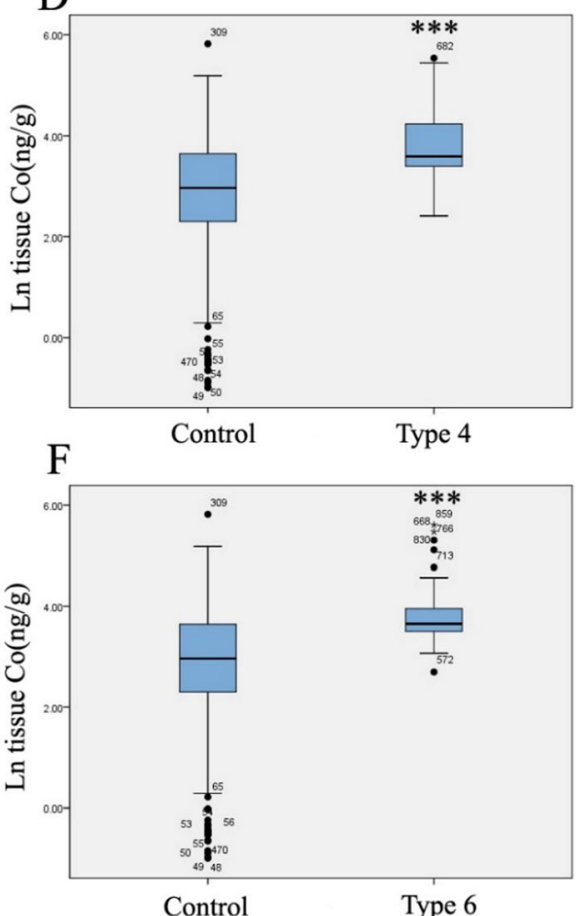

Fig. 3 Levels of cobalt in CHD subtypes and control groups in fetus placental tissues. Boxplots of cobalt levels (Napierian logarithm transformed) of fetus placental tissue samples. The line inside the box = medians; the box length = interquartile range (IQR); the upper and lower ends = 95 and $5 \%$ value. One-sample Kolmogorov-Smirnov test was used to verify the distributions of cobalt. ${ }^{* *} P<0.01$ or ${ }^{* *} P<0.001$, cases compared to the control group. Type1, septal defect; type 2, conotruncal defects; type 3, right ventricular outflow tract obstruction; type 4, left ventricular outflow tract obstruction; type 5, anomalous pulmonary venous return; type 6, other heart defects 
and 5-95\% ranges. Differences in cobalt levels between the case and control groups were assessed by WilcoxonMann-Whitney tests.

The association between the risks of CHDs and cobalt exposure was assessed by crude odds ratios (cORs), adjusted odds ratios (aORs), and 95\% confidence intervals (95\% CIs) using logistic regression. The potential confounding effects were maternal age, gestational age, body mass index (BMI), education, parental smoking habits, folic acid supplementation, and iron and calcium concentration.

The transformed cobalt concentration was normalized using the Napierian logarithm and divided into tertiles (low, medium, and high), and the first tertile of cobalt (hair cobalt: $\leq 0.0210 \mathrm{ng} / \mathrm{mg}$, fetal placental cobalt: $\leq$ $19.8281 \mathrm{ng} / \mathrm{g}$ ) was considered the reference. Two-tailed $P$ values $<0.05$ and $95 \%$ CIs excluding 1.00 were considered statistically significant.

\section{Results}

\section{Characteristics of participants}

During the study period, all 1776 mothers were recruited. According to the exclusion criteria, 568 cases were excluded due to extracardiac abnormalities in case group or any malformations detected after births in

Table 4 Risks for fetal CHD in different maternal hair cobalt concentrations

\begin{tabular}{|c|c|c|c|c|}
\hline Group & Total hair Co & $\begin{array}{l}\text { Hair low } n=197 \\
(<0.0161 \mathrm{ng} / \mathrm{mg})\end{array}$ & $\begin{array}{l}\text { Hair medium } n=199 \\
(0.0161 \mathrm{ng} / \mathrm{mL}-0.0435 \mathrm{ng} / \mathrm{mg})\end{array}$ & $\begin{array}{l}\text { Hair high } n=197 \\
(>0.0435 \mathrm{ng} / \mathrm{mg}) \\
\end{array}$ \\
\hline Control $(n)$ & 325 & 153 & 87 & 85 \\
\hline All cases $(n)$ & 268 & 44 & 112 & 112 \\
\hline $\mathrm{COR}$ & $1.761^{* * *}$ & Reference & $4.476^{* * *}$ & $4.582^{* * *}$ \\
\hline $\mathrm{aOR}$ & 0.090 & Reference & $3.035^{* * *}$ & $1.995^{*}$ \\
\hline $95 \% \mathrm{Cl}$ & $0.004-2.264$ & & $1.809-5.092$ & $1.116-3.569$ \\
\hline Case with septal defects $(n)$ & 182 & 27 & 78 & 77 \\
\hline $\mathrm{COR}$ & 1.652 & Reference & $5.080^{* * *}$ & $5.133^{* * *}$ \\
\hline $\mathrm{aOR}$ & 0.148 & Reference & $4.183^{* * *}$ & $2.544^{* *}$ \\
\hline $95 \% \mathrm{Cl}$ & $0.006-3.815$ & & $2.283-7.664$ & $1.289-5.021$ \\
\hline Case with conotruncal defects $(n)$ & 133 & 21 & 59 & 53 \\
\hline $\mathrm{cOR}$ & 1.528 & Reference & $4.941^{* * *}$ & $4.543^{* * *}$ \\
\hline $\mathrm{aOR}$ & 0.001 & Reference & $3.133^{* * *}$ & 1.885 \\
\hline $95 \% \mathrm{Cl}$ & $0.001-1.865$ & & $1.628-6.029$ & $0.899-3.952$ \\
\hline Case with right ventricular outflow tract obstruction $(n)$ & 123 & 16 & 54 & 53 \\
\hline $\mathrm{COR}$ & $1.627^{* *}$ & Reference & $5.935^{* * *}$ & $5.962^{* * *}$ \\
\hline $\mathrm{aOR}$ & 0.016 & Reference & $3.657^{* * *}$ & $2.717^{* * *}$ \\
\hline $95 \% \mathrm{Cl}$ & $0.001-7.969$ & & $1.805-7.408$ & $1.251-5.902$ \\
\hline Case with left ventricular outflow tract obstruction $(n)$ & 41 & 5 & 20 & 16 \\
\hline $\mathrm{COR}$ & $1.679^{* *}$ & Reference & $7.034^{* * *}$ & $5.760^{* *}$ \\
\hline $\mathrm{aOR}$ & 0.553 & Reference & $4.168^{* * *}$ & 2.701 \\
\hline $95 \% \mathrm{Cl}$ & $0.020-15.498$ & & $1.254-13.854$ & $0.719-10.150$ \\
\hline Case with anomalous pulmonary venous return ( $n$ ) & 42 & 8 & 19 & 15 \\
\hline cOR & $1.483^{*}$ & Reference & $4.177^{* *}$ & $3.375^{* *}$ \\
\hline $\mathrm{aOR}$ & 0.003 & Reference & 2.585 & 0.969 \\
\hline $95 \% \mathrm{Cl}$ & $0.001-138.136$ & & $0.991-6.746$ & $0.296-3.174$ \\
\hline Case with other heart defects $(n)$ & 48 & 10 & 18 & 20 \\
\hline cOR & $1.521^{* *}$ & Reference & $3.166^{* *}$ & $3.600^{* *}$ \\
\hline $\mathrm{aOR}$ & 0.004 & Reference & 1.330 & 1.255 \\
\hline $95 \% \mathrm{Cl}$ & $0.001-156.466$ & & $0.500-3.536$ & $0.424-3.710$ \\
\hline
\end{tabular}

$n$ number, $a O R$ adjusted odds ratio, cOR crude odds ratio

Logistic regression was used to calculate odds ratios and $95 \% \mathrm{Cls}$; the low-medium-high concentration of cobalt are referring to the tertiles and lose-dose group of cobalt was consider as a reference; all models were adjusted for maternal age, gestational age, education, taking folic acid (yes, no), parental smoking (yes, no), maternal pre-pregnancy BMI and iron, and calcium concentration. Significant differences between the mothers of case and control were indicated by the following: ${ }^{*} P<0.05,{ }^{* *} P<0.01$ or ${ }^{* * *} P<0.001$ 
control group. Additionally, 228 mothers were excluded due to loss of collection of specimens. The total number of hair samples was 595. The number of hair samples in the case group and control group was 269 and 326, respectively. The total number of placental tissue samples was 393, and the number of placental tissue samples in the case group and control group was 181 and 212, respectively. The maternal characteristics of the samples are listed in Table 1. Gestational age, folic acid supplementation, parental smoking, and education level of the mother were significantly different between the two groups $(P<0.05)$, while there were no significant differences in maternal age $(P=0.099)$ and BMI $(P=0.136)$.

\section{Cobalt concentration in hair samples}

Levels of metal hair cobalt were compared between the control and case groups. The median concentrations (595\% range) of hair cobalt in the control and case groups were $0.023 \mathrm{ng} / \mathrm{mg}(0.007-1.174 \mathrm{ng} / \mathrm{mg})$ and $0.033 \mathrm{ng} / \mathrm{mg}$ (0.016-0.134 ng/mg), respectively (Table 2$)$. The hair cobalt concentrations in subtypes of CHDs are presented in Table 2. There were significant differences $(P<0.001)$ between each CHD subtype for cases and controls. After the value was Napierian logarithm transformed, the concentrations of hair cobalt in the CHD group were significantly higher than those in the control group $(P<0.001)$ (Figs. 1 and 2$)$.

\section{Cobalt levels in fetal placental tissues}

The median (5-95\% range) fetal placental cobalt concentrations were $19.350 \mathrm{ng} / \mathrm{g}$ (0.617 to $97.834 \mathrm{ng} / \mathrm{g}$ ) and
$42.500 \mathrm{ng} / \mathrm{g}$ (14.431 to $241.959 \mathrm{ng} / \mathrm{g}$ ) in the control and case groups, respectively, which indicated that the concentration of fetal placental cobalt in the case group was significantly higher than that in the control group $(P<$ 0.001). Fetal placental cobalt levels in each CHD subtype were significantly higher than those in controls $(P<0.01)$ (Table 3). As shown in Fig. $1 \mathrm{c}$ and d, the distribution of cobalt in placental tissues was not normal. The data indicated that the concentrations of fetal placental tissue cobalt in the CHD group were significantly higher than that in the control group $(P<0.001)$ (Figs. 1 and 3$)$.

\section{Maternal hair cobalt exposure and CHD risk}

Logistic regression analysis showed that the overall risk of CHDs increases with hair cobalt concentrations (total CHDs aOR, 0.090; 95\% CI, 0.004-2.264) after adjustment for potential risk factors. As shown in Table 4 and Fig. 4, significant differences were found in the middle and high concentrations of cobalt in total CHDs (middle cobalt level group, aOR, 3.035, 95\% CI, 1.809-5.092, $P<$ 0.001; high cobalt level group, aOR, 1.995, 95\% CI, 1.116-3.569, $P<0.05)$. Similar results were found in the septal defect group (middle cobalt level group, aOR, 4.183; 95\% CI 2.283-7.664; $P<0.001$; high cobalt level group, aOR, 2.544; 95\% CI, 1.289-5.021; $P<0.01$ ), conotruncal defects (middle cobalt level group, aOR, 3.133; 95\% CI 1.628-6.029; $P<0.001$ ), right ventricular outflow tract obstruction (aOR, 3.657; 95\% CI 1.805-7.408; $P<$ 0.001; high cobalt level group, aOR, $2.717 ; 95 \% \mathrm{CI}$, 1.251-5.902; $P<0.05$ ), and left ventricular outflow tract

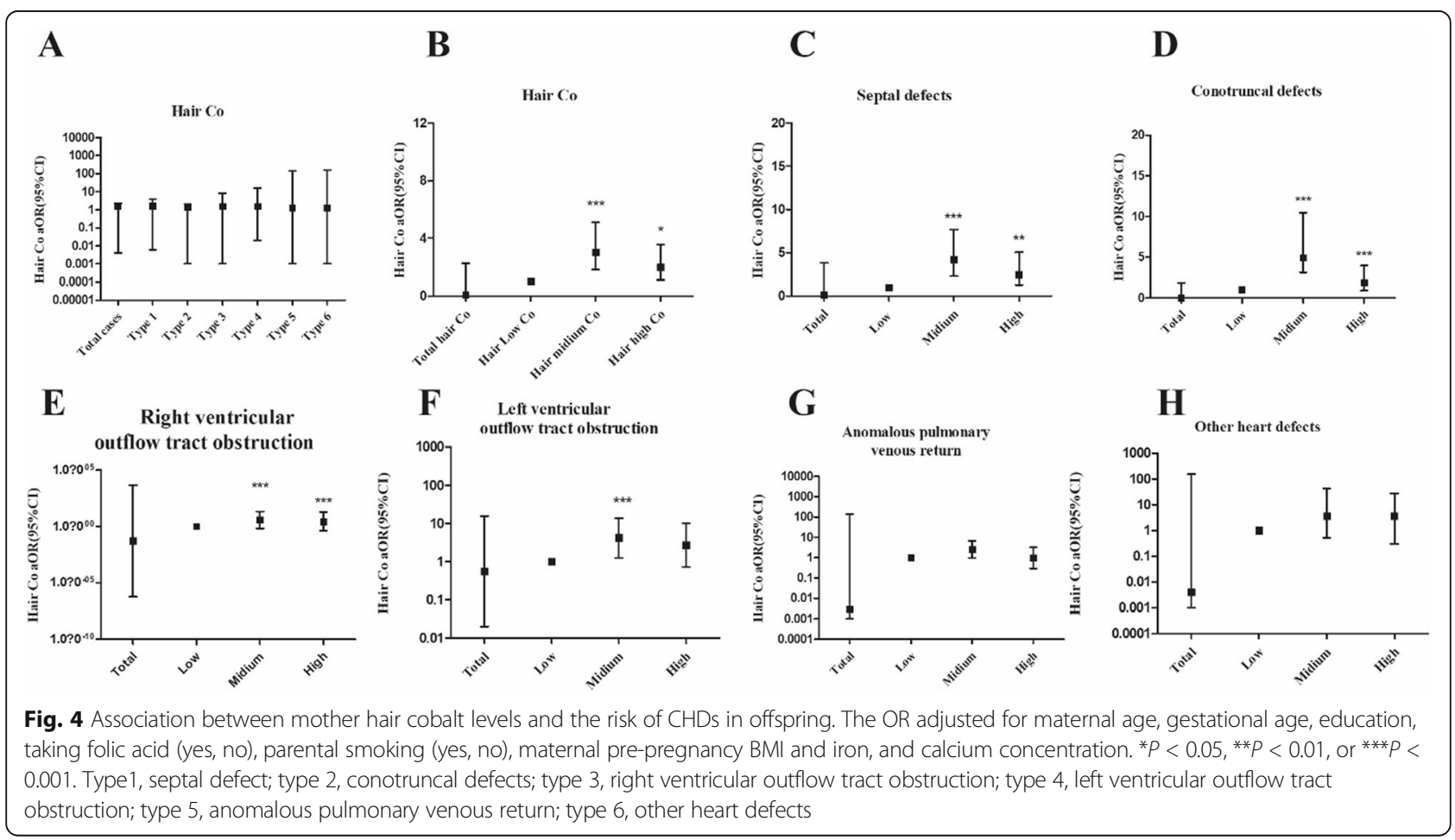


obstruction (middle cobalt level group, aOR, 4.168; 95\% CI 1.254-13.854; $P<0.05$ ) (Table 4 and Fig. 4). All the results indicated that hair cobalt exposure may increase the risk of CHDs in offspring.

\section{Fetal placental tissue cobalt exposure and CHD risk}

As shown in Table 5, the cobalt level in fetal placental tissue increased the risk of CHDs in offspring (aOR 1.017, 95\% CI 1.010-1.024, $P<0.001$ ). The risk of each subtype of $\mathrm{CHD}$ also increased, including septal defects (aOR, 1.017; 95\% CI, 1.010-1.024; $P<0.001$ ), conotruncal defects (aOR, 1.015; 95\% CI, 1.007-1.022; $P<0.001$ ), right ventricular outflow tract obstruction (aOR, 1.022; 95\% CI, 1.013-1.031; $P<0.001)$, left ventricular outflow tract obstruction (aOR, 1.012, 95\% CI, 1.003-1.021; $P<$ $0.05)$, anomalous pulmonary venous return (aOR, 1.013, 95\% CI, 1.004-1.023; $P<0.01$ ), and other heart defects (aOR, 1.013, 95\% CI, 1.004-1.022; $P<0.001$ ) compared with controls. The risk of CHDs and different levels of cobalt in fetal placental tissues was analyzed by trisecting the concentrations of all subjects. Table 5 and Fig. 5 show that exposure to the medium and highest fetal placental concentrations was associated with increased risks of all subtypes of CHDs $(P<0.01)$, except for anomalous

Table 5 Risks for fetal CHD subtypes in different fetal placental tissue cobalt levels

\begin{tabular}{|c|c|c|c|c|}
\hline Group & Total tissue $\mathrm{Ni}$ & $\begin{array}{l}\text { Tissue low, } n=131 \\
(<39.853 \mathrm{ng} / \mathrm{g})\end{array}$ & $\begin{array}{l}\text { Tissue medium, } n=131 \\
(39.853-75.894 \mathrm{ng} / \mathrm{g})\end{array}$ & $\begin{array}{l}\text { Tissue high, } n=131 \\
(>75.894 \mathrm{ng} / \mathrm{g})\end{array}$ \\
\hline Control $(n)$ & 212 & 109 & 58 & 45 \\
\hline All cases $(n)$ & 181 & 22 & 73 & 86 \\
\hline $\mathrm{COR}$ & $2.850^{* * *}$ & Reference & $6.236^{* * *}$ & $9.469^{* * *}$ \\
\hline $\mathrm{aOR}$ & $1.017^{* * *}$ & Reference & $5.777^{* * *}$ & $8.162^{* * *}$ \\
\hline $95 \% \mathrm{Cl}$ & $1.010-1.024$ & & $3.185-10.480$ & $4.379-15.212$ \\
\hline Case with septal defects $(n)$ & 124 & 14 & 46 & 64 \\
\hline $\mathrm{COR}$ & $2.895^{* * *}$ & Reference & $6.175^{* * *}$ & $11.073^{* * *}$ \\
\hline $\mathrm{aOR}$ & $1.017^{* * *}$ & Reference & $5.846^{* * *}$ & $9.230^{* * *}$ \\
\hline $95 \% \mathrm{Cl}$ & $1.010-1.024$ & & $2.904-11.769$ & $4.519-13.347$ \\
\hline Case with conotruncal defects $(n)$ & 96 & 14 & 38 & 44 \\
\hline $\mathrm{cOR}$ & $2.568^{* * *}$ & Reference & $5.101^{* * *}$ & $7.613^{* * *}$ \\
\hline $\mathrm{aOR}$ & $1.015^{* * *}$ & Reference & $4.853^{* * *}$ & $6.354^{* * *}$ \\
\hline $95 \% \mathrm{Cl}$ & $1.007-1.022$ & & $2.380-9.896$ & $3.025-13.347$ \\
\hline Case with right ventricular outflow tract obstruction $(n)$ & 65 & 5 & 21 & 39 \\
\hline $\mathrm{COR}$ & $3.610^{* * *}$ & Reference & $7.893^{* * *}$ & $18.893^{* * *}$ \\
\hline $\mathrm{aOR}$ & $1.022^{* * *}$ & Reference & $8.014^{* * *}$ & $19.164^{* * *}$ \\
\hline $95 \% \mathrm{Cl}$ & $1.013-1.031$ & & $2.800-22.933$ & $6.723-54.632$ \\
\hline Case with left ventricular outflow tract obstruction $(n)$ & 29 & 4 & 12 & 13 \\
\hline $\mathrm{COR}$ & $2.454^{* * *}$ & Reference & $5.638^{* *}$ & $7.872^{* *}$ \\
\hline $\mathrm{aOR}$ & $1.012^{* * *}$ & Reference & $5.551^{* * *}$ & $7.550^{* * *}$ \\
\hline $95 \% \mathrm{Cl}$ & $1.003-1.021$ & & $1.669-18.465$ & $2.112-26.995$ \\
\hline Case with anomalous pulmonary venous return $(n)$ & 26 & 5 & 9 & 12 \\
\hline $\mathrm{cOR}$ & $2.301^{* * *}$ & Reference & $3.383^{*}$ & $5.813^{* *}$ \\
\hline $\mathrm{aOR}$ & $1.013^{* * *}$ & Reference & $3.023^{* *}$ & $4.589^{* * *}$ \\
\hline $95 \% \mathrm{Cl}$ & $1.004-1.023$ & & $0.938-9.740$ & $1.436-14.664$ \\
\hline Case with other heart defects $(n)$ & 32 & 1 & 21 & 10 \\
\hline cOR & $2.695^{* * *}$ & Reference & $39.466^{* * *}$ & $24.222^{* *}$ \\
\hline $\mathrm{aOR}$ & $1.013^{* *}$ & Reference & $36.664^{* * *}$ & $22.082^{* *}$ \\
\hline $95 \% \mathrm{Cl}$ & $1.004-1.022$ & & $4.727-284.371$ & $2.636-184.948$ \\
\hline
\end{tabular}

$n$ number, $a O R$ adjusted odds ratio, $c O R$ crude odds ratio

Logistic regression was used to calculate odds ratios and $95 \% \mathrm{Cls}$; the low-medium-high concentration of cobalt are referring to the tertiles and lose-dose group of cobalt was consider as a reference; all models were adjusted for maternal age, gestational age, education, taking folic acid (yes, no), parental smoking (yes, no), maternal pre-pregnancy BMI and iron, and calcium concentration. Significant differences between the mothers of case and control were indicated by the following: ${ }^{*} P<0.05,{ }^{* * *} P<0.001$ or ${ }^{* *} P<0.01$ 


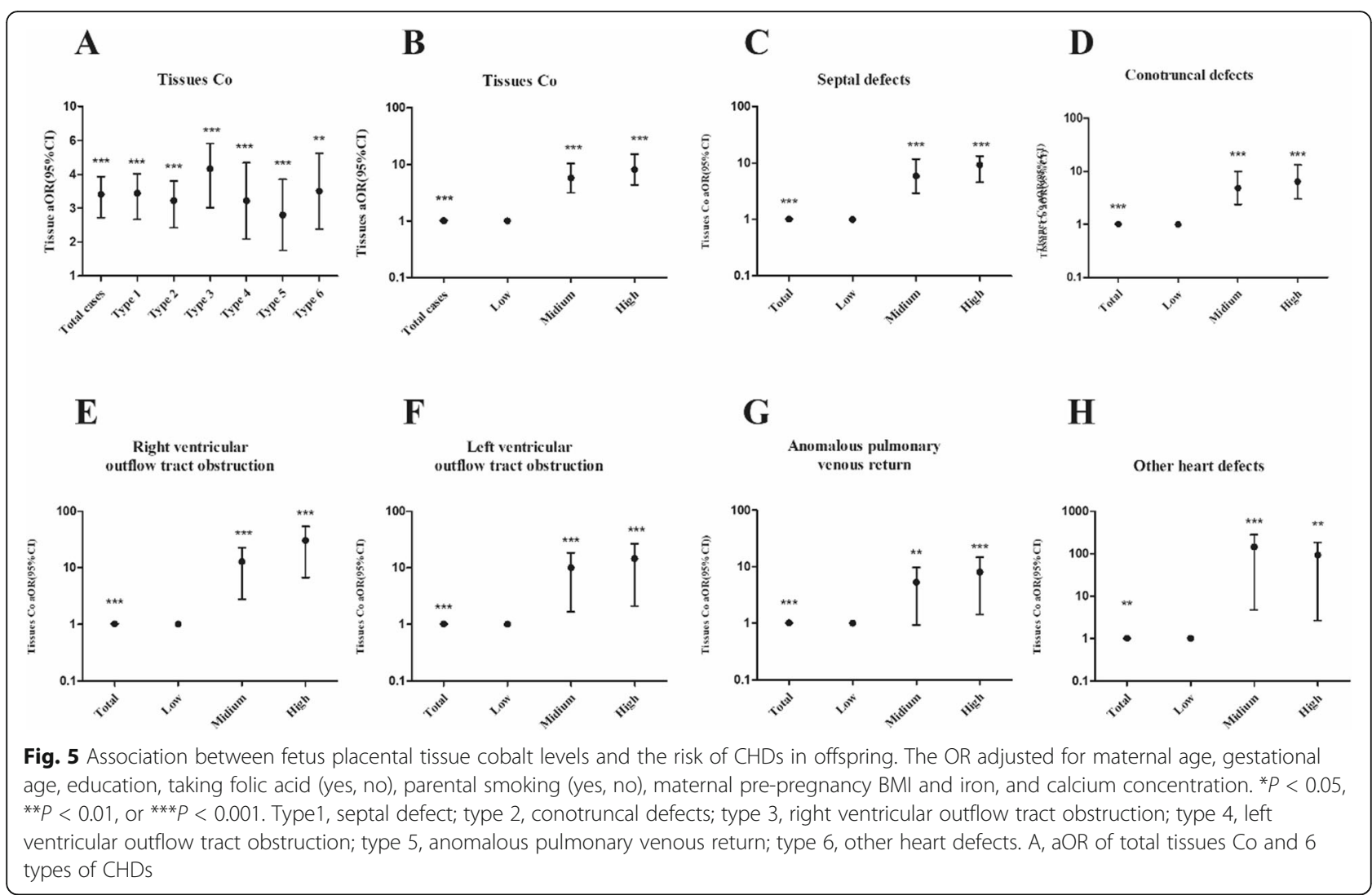

pulmonary venous return subtype. The results suggested that the association between the cobalt level and CHD risk may also display a dose-response relationship in all the subtypes except for the other heart defects.

\section{Discussion}

The study showed that the levels of cobalt in maternal hair samples and fetal placental tissues were both higher in the CHD groups than levels in the control groups (Table 2 and Table 3). Logistic analysis indicated that maternal exposure to cobalt had a significant association with the risk of CHDs in offspring, and higher concentrations of cobalt may increase the risk of CHDs in some subtypes in offspring (Tables 4 and 5 and Figs. 4 and 5).

CHDs were caused by inherited factors, environmental exposure, or both [33, 34]. Metal exposure was one of the pathogenic factors [35]. Other metals, such as lead, arsenic, and barium, were associated with the occurrence of CHDs in offspring [12, 35]. Placental chromium, manganese, and lead have been reported to be toxic to children [36]. Cobalt ions were more bioavailable to interact with various cellular receptors, biomolecules, and ion channels $[18,22]$. In the study, logistic analysis was adjusted for iron concentration and calcium concentration that was because iron could significantly inhibit the absorption of cobalt in both dietary cobalt treatments [37]. Besides, cobalt causes contraction of vascular smooth muscle depending activation of calcium channels in the plasma membrane [38]. Although cobalt had many physiological implications, cobalt toxicity had been shown in heart, liver, lung, and the neurological system $[27,39]$. Our study provided evidence for the cardiac toxicity of chronic cobalt exposure in pregnant women. Pregnant women might have little acute occupational exposure to cobalt, but avoiding environmental exposure was more difficult to anticipate, measure, or control.

In order to observe the long-term cobalt exposure of pregnant mothers, hair samples were utilized. Hair samples may even provide us with information regarding the metal exposure of the mother prior to pregnancy. In addition, cobalt in fetal placental tissues was also analyzed in the study. Cobalt levels in fetal placental tissues could directly display cobalt exposure during pregnancy. Besides, the samples were recruited in multiple hospitals in different provinces of China, and the sample size of pregnant women was superior in previous studies, which could reflect the exposure of cobalt in different areas in China during pregnancy.

Our study had many limitations. First, the mechanism of cobalt exposure-induced CHDs has not been shown in this study, and further studies are warranted to clarify the underlying mechanisms. The possible mechanisms of the toxic effect of cobalt were that cobalt could attack fatty acids and convert them to free radical lipids and free 
radical lipid peroxidation, leading to damage to the cell membrane fluidity and interruption of reactive oxygen species [40]. Cobalt ions could occupy the combining site of calcium and ions and inhibit the activity of $\mathrm{Ca}^{2+}$ ATPase, which may impair heart development [18]. Second, this study did not consider interactions between cobalt and all the other metals except calcium and ions. This was because cobalt $\left(\mathrm{Co}^{2+}\right)$ uptake appears to be shared with calcium [22], and cobalt gastrointestinal absorption involves mechanisms with ions [18]. This is an area that should be further investigated in future studies. Third, other samples, such as urine and serum, should be studied in the future. Fourth, our study showed that cobalt exposure was related to CHD occurrence in offspring. However, the range of the $95 \% \mathrm{CI}$ was wide, perhaps because of the small number of CHDs. Further studies are needed to recruit more $\mathrm{CHD}$ cases in the future.

\section{Conclusion}

We observed an association between the cobalt concentrations in maternal and fetal placental tissues and the increased risk of CHDs in the general pregnant population with exposure to cobalt.

\section{Abbreviations}

CHD: Congenital heart disease; aOR: Adjusted odds ratio; cOR: Crude odds ratio; 95\% Cl: 95\% confidence interval; GM: Geometric mean; BMl: Body mass index; ICP-MS: Inductively coupled plasma mass spectrometry

\section{Acknowledgements}

We thank all participating families for their cooperation and for providing personal information. We thank the obstetricians, pediatricians, pathologists, experimental technicians, and other participants involved in the project for recruiting the case and control participants and collecting the data.

\section{Authors' contributions}

The design of study was supported by Jun Zhu. Sample collection and data collection of the study were supported by Shuihua Yang, Jiaxiang Yang, Ying Deng, Sheng-li Li, Nana Li, Ping Yu, and Xinlin Chen. The interpretation of data and the writing of the manuscript were supported by Nannan Zhang and Zhen Liu. The authors read and approved the final manuscript.

\section{Funding}

The design and collection and data analysis of the study were supported by the National Key Research and Development Program of China (No. 2016YFC1000102), the National Natural Science Foundation of China (No. 81573165 and No. 81970738), Special Foundation for State Basic Research Program of China (No. 2014FY110700), and Key Research and Development Program of Sichuan Province (2020YFS0071).

\section{Ethics approval and consent to participate}

The program was approved by the Ethics Committee of Sichuan University (No. 2010004), and informed consent was obtained from all subjects during the enrolment process. Informed and signed consent was received from each participant

\section{Consent for publication}

Consent for publication for research purpose was taken from the participant.

\section{Competing interests}

The authors declare that they have no competing interests.

\section{Author details}

${ }^{1}$ National Center for Birth Defect Monitoring, Key Laboratory of Birth Defects and Related Diseases of Women and Children, Ministry of Education, West China Second University Hospital, and State Key Laboratory of Biotherapy, Sichuan University, Sec. 3 No.17, South Ren Min Road, Chengdu 610041, Sichuan, People's Republic of China. ${ }^{2}$ Department of Ultrasound, Maternal and Child Healthcare Hospital of Guangxi Zhuang Autonomous Region, Nanning, Guangxi, People's Republic of China. ${ }^{3}$ Department of Ultrasound, Sichuan Maternal and Child Healthcare Hospital, Chengdu 610041, Sichuan, People's Republic of China. ${ }^{4}$ Department of Ultrasound, Shenzhen Maternity and Child Healthcare Hospital, Shenzhen, Guangdong, People's Republic of China. ${ }^{5}$ Department of Ultrasound, Hubei Maternal and Child Healthcare Hospital, Wuhan, Hubei, People's Republic of China.

Received: 17 February 2020 Accepted: 28 July 2020

Published online: 08 August 2020

\section{References}

1. Auger N, Fraser WD, Sauve R, Bilodeau-Bertrand M, Kosatsky T. Risk of congenital heart defects after ambient heat exposure early in pregnancy. Environ Health Perspect. 2017;125:8-14. https://doi.org/10.1289/EHP171.

2. Vecoli C, Pulignani S, Foffa I, Andreassi MG. Congenital heart disease: the crossroads of genetics, epigenetics and environment. Curr Genomics. 2014; 15:390-9. https://doi.org/10.2174/1389202915666140716175634.

3. Verheugt CL, Uiterwaal CS, Vaartjes I, van der Velde ET, Zomer AC, Meijboom FJ, et al. Chance of surgery in adult congenital heart disease. Eur J Prev Cardiol. 2017. https://doi.org/10.1177/2047487317710355.

4. Giamberti A, Varrica A, Pome G, Micheletti A, Negura D, Ranucci M, et al. The care for adults with congenital heart disease: organization and function of a grown-up congenital heart disease unit. Eur Heart J Suppl. 2016;18:E15E8. https://doi.org/10.1093/eurheartj/suw011.

5. Hoffman J. The global burden of congenital heart disease. Cardiovasc J Africa. 2013;24:141-5. https://doi.org/10.5830/CVJA-2013-028.

6. Moore-Morris T, van Vliet PP, Andelfinger G, Puceat M. Role of epigenetics in cardiac development and congenital diseases. Physiol Rev. 2018;98:245375. https://doi.org/10.1152/physrev.00048.2017.

7. Huang JB, Liu YL, LV XD. Pathogenic mechanisms of congenital heart disease. Fetal Pediatric Pathol. 2010;29:359-72. https://doi.org/10.3109/ 15513811003789628

8. Gilboa SM, Desrosiers TA, Lawson C, Lupo PJ, Riehle-Colarusso TJ, Stewart PA, et al. Association between maternal occupational exposure to organic solvents and congenital heart defects, National Birth Defects Prevention Study, 1997-2002. Occup Environ Med. 2012;69:628-35. https://doi.org/10. 1136/oemed-2011-100536.

9. Llurba Olive E, Xiao E, Natale DR, Fisher SA. Oxygen and lack of oxygen in fetal and placental development, feto-placental coupling, and congenital heart defects. Birth Defects Res. 2018;110:1517-30. https://doi.org/10.1002/ bdr2.1430.

10. Stingone JA, Luben TJ, Carmichael SL, Aylsworth AS, Botto LD, Correa A, et al. Maternal exposure to nitrogen dioxide, intake of methyl nutrients, and congenital heart defects in offspring. Am J Epidemiol. 2017;186:719-29. https://doi.org/10.1093/aje/kwx139.

11. Jin X, Tian X, Liu Z, Hu H, Li X, Deng Y, et al. Maternal exposure to arsenic and cadmium and the risk of congenital heart defects in offspring. Reprod Toxicol. 2016;59:109-16. https://doi.org/10.1016/j.reprotox.2015.12.007.

12. Zhang N, Liu Z, Tian X, Chen M, Deng Y, Guo Y, et al. Barium exposure increases the risk of congenital heart defects occurrence in offspring. Clin Toxicol (Phila). 2018;56:132-9. https://doi.org/10.1080/15563650.2017. 1343479.

13. Liang C, Wang J, Xia X, Wang Q, Li Z, Tao R, et al. Serum cobalt status during pregnancy and the risks of pregnancy-induced hypertension syndrome: a prospective birth cohort study. J Trace Elem Med Biol. 2018;46: 39-45. https://doi.org/10.1016/j.jtemb.2017.11.009.

14. Suh M, Thompson CM, Brorby GP, Mittal L, Proctor DM. Inhalation cancer risk assessment of cobalt metal. Reg Toxicol Pharmacol. 2016;79:74-82. https://doi.org/10.1016/j.yrtph.2016.05.009.

15. Catalani S, Rizzetti MC, Padovani A, Apostoli P. Neurotoxicity of cobalt. Hum Exp Toxicol. 2012;31:421-37. https://doi.org/10.1177/0960327111414280.

16. Li ZJ, Liang CM, Xia X, Huang K, Yan SQ, Tao RW, et al. Association between maternal and umbilical cord serum cobalt concentration during pregnancy and the risk of preterm birth: the Ma'anshan birth cohort (MABC) study. 
Chemosphere. 2019;218:487-92. https://doi.org/10.1016/j.chemosphere.2018. 11.122.

17. Arnich $N$, Sirot V, Riviere G, Jean J, Noel L, Guerin T, et al. Dietary exposure to trace elements and health risk assessment in the 2nd French Total Diet Study. Food Chem Toxicol. 2012;50:2432-49. https://doi.org/10.1016/j.fct. 2012.04.016.

18. Leyssens L, Vinck B, Van Der Straeten C, Wuyts F, Maes L. Cobalt toxicity in humans-a review of the potential sources and systemic health effects. Toxicology. 2017;387:43-56. https://doi.org/10.1016/j.tox.2017.05.015.

19. Klasson M, Lindberg M, Bryngelsson IL, Arvidsson H, Pettersson C, Husby B, et al. Biological monitoring of dermal and air exposure to cobalt at a Swedish hard metal production plant: does dermal exposure contribute to uptake? Contact Dermatitis. 2017;77:201-7. https://doi.org/10.1111/cod. 12790.

20. Lantin AC, Vermeulen J, Mallants A, Vanoverschelde JL, Speybroeck N, Swennen $B$, et al. Occupational exposure to cobalt is not associated with incipient signs of dilated cardiomyopathy in a Belgian refinery. Occup Environ Med. 2013;70:386-92. https://doi.org/10.1136/oemed-2012-100930.

21. Finley BL, Monnot AD, Paustenbach DJ, Gaffney SH. Derivation of a chronic oral reference dose for cobalt. Reg Toxicol Pharmacol. 2012;64:491-503. https://doi.org/10.1016/j.yrtph.2012.08.022.

22. Simonsen LO, Harbak H, Bennekou P. Cobalt metabolism and toxicology--a brief update. Sci Total Environ. 2012;432:210-5. https://doi.org/10.1016/j. scitotenv.2012.06.009.

23. Xie H, Smith LJ, Holmes AL, Zheng T, Pierce Wise J Sr. The cytotoxicity and genotoxicity of soluble and particulate cobalt in human lung epithelial cells. Environ Mol Mutagen. 2016;57:282-7. https://doi.org/10.1002/em.22009.

24. Awoyemi OV, Okotie UJ, Oyagbemi AA, Omobowale TO, Asenuga ER, OlaDavies $\mathrm{OE}$, et al. Cobalt chloride exposure dose-dependently induced hepatotoxicity through enhancement of cyclooxygenase-2 (COX-2)/B-cell associated protein $\mathrm{X}(\mathrm{BAX})$ signaling and genotoxicity in Wistar rats. Environ Toxicol. 2017;32:1899-907. https://doi.org/10.1002/tox.22412.

25. Zheng F, Luo Z, Zheng C, Li J, Zeng J, Yang H, et al. Comparison of the neurotoxicity associated with cobalt nanoparticles and cobalt chloride in Wistar rats. Toxicol Appl Pharmacol. 2019;369:90-9. https://doi.org/10.1016/j. taap.2019.03.003

26. Kirkland D, Brock T, Haddouk H, Hargeaves V, Lloyd M, Mc Garry S, et al. New investigations into the genotoxicity of cobalt compounds and their impact on overall assessment of genotoxic risk. Reg Toxicol Pharmacol. 2015;73:311-38. https://doi.org/10.1016/j.yrtph.2015.07.016.

27. Linna A, Oksa P, Groundstroem K, Halkosaari M, Palmroos P, Huikko S, et al. Exposure to cobalt in the production of cobalt and cobalt compounds and its effect on the heart. Occup Environ Med. 2004;61:877-85. https://doi.org/ 10.1136/oem.2003.009605.

28. M P. Cobalt cardiomyopathy: a critical reappraisal in light of a recent resurgence Circ Heart Fail. 2016;9.

29. Oyagbemi AA, Omobowale TO, Awoyomi OV, Ajibade TO, Falayi OO, Ogunpolu BS, et al. Cobalt chloride toxicity elicited hypertension and cardiac complication via induction of oxidative stress and upregulation of COX-2/Bax signaling pathway. Hum Exp Toxicol. 2018. https://doi.org/10. 1177/0960327118812158.38(5):519-32.

30. Wang Z, Chen Z, Zuo Q, Song F, Wu D, Cheng W, et al. Reproductive toxicity in adult male rats following intra-articular injection of cobaltchromium nanoparticles. J Orthop Sci. 2013;18:1020-6. https://doi.org/10. 1007/s00776-013-0458-2.

31. Liu Z, Yu Y, Li X, Wu A, Mu M, Li N, et al. Maternal lead exposure and risk of congenital heart defects occurrence in offspring. Reprod Toxicol. 2015;51:16. https://doi.org/10.1016/.j.reprotox.2014.11.002.

32. Karimi G, Shahar S, Homayouni N, Rajikan R, Abu Bakar NF, Othman MS Association between trace element and heavy metal levels in hair and nail with prostate cancer. Asian Pac J Cancer Prev. 2012;13:4249-53.

33. Feng $Y, Y u$ D, Yang $L, D a M$, Wang $Z$, Lin $Y$, et al. Maternal lifestyle factors in pregnancy and congenital heart defects in offspring: review of the current evidence. Ital J Pediatr. 2014;40:85. https://doi.org/10.1186/s13052-014-0085-3.

34. Kuciene R, Dulskiene V. Maternal socioeconomic and lifestyle factors during pregnancy and the risk of congenital heart defects. Medicina (Kaunas). 2009; 45:904-9.

35. Ou Y, Bloom MS, Nie Z, Han F, Mai J, Chen J, et al. Associations between toxic and essential trace elements in maternal blood and fetal congenital heart defects. Environ Int. 2017;106:127-34. https://doi.org/10.1016/j.envint. 2017.05.017.
36. Amaya E, Gil F, Freire C, Olmedo P, Fernandez-Rodriguez M, Fernandez MF, et al. Placental concentrations of heavy metals in a mother-child cohort. Environ Res. 2013;120:63-70. https://doi.org/10.1016/j.envres.2012.09.009.

37. Reuber S, Kreuzer M, Kirchgessner M. Interactions of cobalt and iron in absorption and retention. J Trace Elem Electrolytes Health Dis. 1994;8:151-8.

38. Gallagher MJ, Alade PI, Dominiczak AF, Bohr DF. Cobalt contraction of vascular smooth muscle is calcium dependent. J Cardiovasc Pharmacol. 1994;24:293-7.

39. Liu YK, Xu H, Liu F, Tao R, Yin J. Effects of serum cobalt ion concentration on the liver, kidney and heart in mice. Orthop Surg. 2010;2:134-40. https:// doi.org/10.1111/j.1757-7861.2010.00076.x.

40. Zeeshan M, Murugadas A, Ghaskadbi S, Ramaswamy BR, Akbarsha MA. Ecotoxicological assessment of cobalt using Hydra model: ROS, oxidative stress, DNA damage, cell cycle arrest, and apoptosis as mechanisms of toxicity. Environ Pollut. 2017;224:54-69. https://doi.org/10.1016/j.envpol. 2016.12.042.

\section{Publisher's Note}

Springer Nature remains neutral with regard to jurisdictional claims in published maps and institutional affiliations.

\section{Ready to submit your research? Choose BMC and benefit from:}

- fast, convenient online submission

- thorough peer review by experienced researchers in your field

- rapid publication on acceptance

- support for research data, including large and complex data types

- gold Open Access which fosters wider collaboration and increased citations

- maximum visibility for your research: over $100 \mathrm{M}$ website views per year

At $\mathrm{BMC}$, research is always in progress.

Learn more biomedcentral.com/submissions 